\title{
O modelo industrial de produção de alimentos sob a perspectiva da sociedade de risco e do princípio da precaução
}

Food production industrial model under the perspective of risk society and precautionary principle

El modelo industrial de producción de alimentos bajo la perspectiva de la sociedad de riesgo y el principio de la precaución

RESUMO. Objetivo: Este artigo analisa as relações entre o modelo de produção industrial de alimentos e a existência, na atualidade, de um grande número de pessoas famintas. Metodologia: Foi usado o método dedutivo, amparado em revisão bibliográfica. Resultados: O modelo de agricultura consistente na utilização de enormes áreas de terra para a plantação de poucos produtos, em sua maioria direcionada ao mercado externo, traz consigo a lógica industrial; é agressivo à natureza e altamente dependente da técnica e da ciência. Este modelo não demonstrou melhorias no sentido de aplacar a fome mundial, uma vez que não produz alimentos, mas sim commodities, de modo que é impositivo verificar se é adequado à sociedade de risco e ao princípio da precaução. A sociedade de risco implica reconhecer a existência de uma série de riscos, que devem ser considerados nas decisões políticas e jurídicas, de modo que o Poder Público aja previamente à ocorrência dos possíveis perigos. Do mesmo modo atua o princípio da precaução, segundo o qual a dúvida sempre vem em benefício do meio ambiente. Conclusão: $O$ uso da natureza não deve conduzir ao esgotamento dos recursos, a situações de risco à segurança alimentar ou à distribuição desigual de alimentos, mas sim à adoção de modelos de produção que coexistam com os ecossistemas e cuja finalidade seja, efetivamente, prover alimentos aos seres vivos.

Palavras-chave: Produção de alimentos. Segurança Alimentar e Nutricional. Agroindústria.

ABSTRACT. Objective: This paper analyses the relations beween the industrial food production model and the existence of a great number of undernourished people nowadays. Methodology: It was used the deductive method, based on a bibliographical review. Results: The model of agriculture consisting in the use of enormous areas of land for the plantation of a few products, mostly for the outland market, was stablished. The model adopted carries the industrial logic; it is aggressive to nature and highly dependent of technique and science. This model showed no improvement to appease world famine, since it produces not food, but commodities, therefore, it is necessary to verify if it is appropriate to the risk society and to the precautionary principle. Risk society implies acknowledging the existence of many risks, which should be considered in political and judicial decisions, so that the governments act previously to the occurrence of possible damages. On the same basis, acts the precautionary principle, according to which the doubt always benefits the environment. Conclusion: The use of nature should not lead to the exhaustion of resources,

\footnotetext{
1 Juíza de direito vinculada ao Tribunal de Justiça do Estado do Rio Grande do Sul. Mestranda do PPGD da Universidade Federal do Rio Grande do Sul. E-mail: julianaetc@hotmail.com
} 
risk situations to food security or unequal distribution of food, but to the adoption of production models which coexist with the environment and whose aim is indeed provide food for the living beings.

Keywords: Food production. Food and Nutrition Security. Agribusiness.

RESUMEN. Objetivo: Este artículo analisa las relaciones entre el modelo de producción industrial de alimentos y la existencia, en la actualidad, de un gran numero de personas hambrientas. Metodología: Fué usado el método deductivo, amparado sobre una revisión bibliográfica. Resultados: El modelo de agricultura consistente en la utilización de largas áreas de tierra para la plantación de pocos productos, la mayoria destinada al mercado externo lleva la lógica industrial, es agresivo a la naturaleza y altamente dependiente de la tecnica y de la ciencia. Ese modelo no ha demostrado mejorías para calmar el hambre mundial, pues no produce alimentos, sino commodities, de modo que es necesario verificar si es adecuado a la sociedad de riesgo y al principio de la precaución. La sociedad de riesgo supone reconocer la existencia de una serie de riesgos, que deben ser considerados en las decisiones políticas y jurídicas, de modo que el Poder Público actúe previamente a la ocurrencia de posibles peligros. De la misma manera, actua el principio de la precaución, según el qual la duda siempre beneficia al medio ambiente. Conclusión: El uso de la naturaleza no debe conducir al agotamiento de los recursos, a situaciones de riesgo a la seguridad alimentar o a la distribución desigual de alimentos, sino a la adopción de modelos de producción que coexistan con los ecosistemas y cuya finalidad sea, efectivamente, suministrar alimentos a los seres vivos.

Palabras-Ilave: Producción de alimentos. Seguridad Alimentaria y Nutricional. Agroindustria.

\section{Introdução}

A batata é um tubérculo nativo dos Andes, cultivado pelos incas por ocasião da conquista pelos europeus e transportado à Espanha no século XVI. A partir do século XVIII, a batata popularizou-se na Europa, tornando-se um dos produtos mais cultivados no continente e no oeste da Inglaterra, bem como base da economia e da dieta alimentar na Irlanda, em especial entre os camponeses, que comiam apenas isso durante o inverno, dado o equilíbrio nutricional desse alimento (1).

$\mathrm{Na}$ Irlanda, a batata era cultivada a partir de uma determinada espécie única melhorada, desenvolvida a partir de pesquisas realizadas mediante o cruzamento e seleção de plantas durante gerações até a obtenção de um exemplar com a combinação adequada de determinadas características. No entanto, na colheita de 1845 , as batatas foram atacadas por uma doença causada por um fungo e, como eram todas oriundas da mesma planta única melhorada, toda a safra foi perdida causando a morte de cerca de 1 milhão de pessoas por inanição, episódio que é conhecido como a "grande fome das batatas". A fome provocou ainda, uma intensa onda emigratória, na qual mais de 1 milhão de pessoas deixaram o país, 
reduzindo drasticamente a população (1).

A "grande fome das batatas" ocorreu há quase duzentos anos, porém a situação que a ensejou não se encontra dissociada da realidade atual. Ao contrário, é possível constatar que, hodiernamente, o planeta encontra-se compartimentalizado, de modo que diferentes regiões produzem diferentes alimentos em grandes quantidades e em imensas extensões de terra. A lógica da produção industrial - dividindo as tarefas entre os indivíduos, de modo que cada um produza em maior quantidade e mais rapidamente - foi transposta para os diferentes países no que concerne à geração de alimentos, sejam estes de origem vegetal ou animal. Dessa maneira, estabeleceram-se as monoculturas - em substituição à agricultura ou extrativismo desenvolvidos pelos povos tradicionais ou comunidades - e a criação industrial de animais - com seus milhões de frangos e outros animais enclausurados em gaiolas ou outros aparelhos de dimensões ínfimas - em lugar da idílica imagem tradicional das fazendas como um lugar tranquilo e longínquo da vida citadina voltada ao lucro (2). Assim, é possível produzir alimentos em grande escala graças ao desenvolvimento da ciência e da técnica.

Todavia, segundo dados da Organização das Nações Unidas para Alimentação e Agricultura (FAO), a partir do Mapa da Fome no mundo, no biênio 2011-2013, 842 milhões de pessoas encontravam-se subnutridas, representando cerca de $12 \%$ da população mundial. No Brasil, conforme dados dessa organização, no mesmo lapso temporal, o contingente de subnutridos é de 13,6 milhões de pessoas, correspondendo a 6,9\% da população. A FAO define a condição de subnutrição ou fome crônica como sendo o estado, com duração de pelo menos um ano, de inabilidade de obter alimentos suficientes, assim definida como um nível de ingestão de alimentos insuficiente para satisfazer os requisitos de energia dietética (3).

Dito isso, afigura-se necessário perquirir se a adoção do modo de produção de alimentos consentâneo com o modelo industrial e capitalista afigura-se adequado ao escopo que deveria pautar toda a produção de alimentos, qual seja alimentar, tendo em vista uma perspectiva que tem por base o reconhecimento da sociedade de risco e o princípio da precaução.

\section{O modelo de produção de alimentos industrial}

A preocupação com a alimentação é um problema que tem acompanhado a 
humanidade desde os seus primórdios, consistindo numa questão determinante para a reprodução das espécies. Em parte da Pré-história, o homem alimentava-se basicamente a partir do extrativismo e da caça. No entanto, entre 11.000 e 8.000 anos atrás, surgiu a agricultura simultaneamente em diversas regiões do globo terrestre, de forma independente entre si. Nesse momento, a espécie humana passou a se diferenciar pela cultura, pois obteve segurança alimentar, inobstante mantivesse suas características biológicas anteriores. É possível afirmar que a evolução da espécie humana, em parte, pode ser associada à sua necessidade de se alimentar, como se verifica a partir da análise da localização das civilizações da Antiguidade, as quais se desenvolveram ao longo dos grandes rios - tais como a egípcia, ao longo do rio Nilo, e a chinesa, ao longo dos rios Amarelo e Azul porquanto esses Ihes permitiam melhor administrar as perdas dos solos e repor a fertilidade (4).

Durante milênios, a produção de alimentos era realizada de modo a fornecer a variedade possível dado o conhecimento técnico que se tinha à época. À agricultura, estava associada, além da pecuária, também o extrativismo, consubstanciado na caça, coleta e pesca, nunca tendo havido propriamente uma substituição desta última atividade por aquela primeira, mas sim a coexistência de ambas (4).

No entanto, com a descoberta da América, os europeus passaram a plantar poucos produtos em áreas de grandes dimensões, utilizando-se, assim, de monoculturas. Essas plantações, na mesma medida em que se expandiam no solo americano, usurpavam os lugares antes ocupados pelos produtos cultivados pelos nativos.

Galeano retrata primorosamente o tratamento concedido pelo conquistador europeu à natureza do Novo Mundo. Narrando a expansão do "Rei Açúcar", revela que as plantações de açúcar eram ditadas pela demanda de ultramar, tendo por base apenas a ganância de seus proprietários a serviço do mercado de consumo europeu e funcionando, em verdade, como um canal para a evasão das riquezas naturais. Cada área de plantação do açúcar teve um ciclo dinâmico após a integração ao mercado mundial. Entretanto, pela substituição por outros produtos, pelo esgotamento do solo ou pelo surgimento de outras áreas com melhores condições, sobreveio a decadência, com a pobreza que lhe caracteriza (5).

No ponto, veja-se que, no início da História brasileira, o Nordeste era a região mais rica; no entanto, na contemporaneidade, é a mais pobre, arrasada que foi pelo "Rei Açúcar", que substituiu a vegetação típica litorânea por suas plantações. A mata tropical que cobria o 
litoral do país converteu-se numa região de savana, assolada pela fome, onde antes havia um solo de grande fertilidade que se prestava adequadamente para alimentar sua população de animais humanos e não humanos. É ainda Galeano que explana, de forma expressiva, a senda dos canaviais:

Los incendios que abrían tierras a los cañaverales devastaron la floresta y con ella la fauna; desaparecieron los ciervos, los jabalíes, los tapires, los conejos, las pacas y los tatúes. La alfombra vegetal, la flora y la fauna fueron sacrificadas, en los altares del monocultivo, a la canã de azúcar. La produccíon extensiva agotó rápidamente los suelos (5).

A mesma narrativa pode ser transposta para outras regiões da América Latina, onde o "ouro branco" imperou - tais como as ilhas do Caribe: Barbados, Jamaica, Haiti etc. - bem como, com ínfimas alterações, para quaisquer regiões onde os produtos tradicionalmente cultivados foram substituídos pelas monoculturas impostas pelo mercado europeu. Da plantação colonial, deriva diretamente o latifúndio, um gargalo que estrangula o desenvolvimento econômico da América Latina e um dos fatores essenciais da marginalização e da pobreza das massas latinoamericanas (5).

Situação semelhante ocorreu na Ásia, a partir da colonização realizada pelas nações europeias, cujas ideias de natureza e cultura constituíram derivações do modelo da fábrica industrial. Na Índia, o governo impôs um modelo de administração florestal dito "científico", a partir da Lei $\mathrm{n}^{\circ}$ VII de 1865, que, em verdade, positivou os interesses comerciais e industriais que existiam sobre as florestas, vistas como detentoras de valor apenas enquanto fornecedoras de madeira para o mercado. Esse modelo de silvicultura constitui um sistema reducionista de saber, que desconsidera as relações existentes entre as diversas formas de vida, os recursos naturais e as comunidades florestais, tratando-os como elementos isolados, e não como parte de um todo complexo, e destruindo a diversidade que é natural à floresta (6).

O mesmo modelo dito científico foi imposto à agricultura naquele país, conduzindo à destruição de espécies que poderiam ser utilizadas como alimento, mas que não poderiam ser vendidas no mercado. Sobre o tema, Shiva lembra que a Revolução Verde expurgou as variedades de sementes das comunidades locais nos países do Terceiro Mundo, tachandoas de primitivas e inferiores. No entanto, essas sementes possuem maior valor nutritivo reconhecido pelas comunidades tradicionais - do que as advogadas pelos técnicos e cientistas da Revolução Verde, cujo valor, na realidade, resume-se ao preço obtido no 
mercado mundial. Da mesma forma, as safras populares são consideradas inconvenientes e destruídas mediante a utilização de venenos (6).

Na Europa e outras regiões temperadas, por outro lado, desenvolveu-se uma espécie de monocultura baseada não apenas numa especialização exacerbada, mas também na expressiva dependência de poucos cultivares, com a consequente vulnerabilidade a pragas e variações climáticas, e de insumos externos (4).

$\mathrm{Na}$ atualidade, pode-se dizer que o planeta encontra-se delimitado conforme a produção de alguns poucos grãos, tais como o arroz, a soja e o milho. No que pertine ao arroz, 68\% de todas as exportações desse grão, em 2001, eram realizadas por apenas quatro países, a saber, Tailândia, Vietnã, Estados Unidos e China. No mesmo ano, somente três países respondiam por $82 \%$ da produção mundial da soja: Estados Unidos, Brasil e Argentina. Quanto ao milho, naquele ano, 78\% das exportações eram efetuadas pelos Estados Unidos e 12\% pela Argentina (4).

De outra banda, a mesma lógica da compartimentalização e do desrespeito para com a natureza guia a criação de animais. Como bem lembrado por Singer, as grandes empresas começaram por controlar a produção de aves e, posteriormente, dos demais animais não humanos destinados ao consumo, gerando um mercado extremamente competitivo, cuja única meta resume-se à venda do seu produto. Não há, destarte, qualquer preocupação com o equilíbrio que deve existir entre plantas, animais e natureza, sendo adotados métodos industriais com a exclusiva finalidade de reduzir custos e aumentar a produção (2). No ponto, ajusta-se perfeitamente à situação do criador industrial a expressão "animal-máquina", decorrente das ideias de Descartes, que retirou dos animais qualquer consideração que lhes poderia ser atribuída, ao compará-los com uma máquina, cujas peças foram elaboradas pelo Deus todo-poderoso que concedeu ao homem - animal não humano - a superioridade da alma (7).

Por oportuno, cabe lembrar que, no início de 2014, os meios de comunicação social veicularam inúmeras notícias acerca das milhares de mortes de frangos ocorridas nos criadouros do Rio Grande do Sul em função do calor excessivo ocorrido no período e de problemas advindos do fornecimento de energia elétrica. No entanto, não restou demonstrada consideração com as vidas perdidas em si mesmas, tampouco com o alimento que deixou de ser fornecido: a preocupação era apenas com as perdas econômicas do 
agronegócio².

A produção de animais para consumo em nível industrial aumentou sobremaneira a quantidade desses seres vivos disponibilizados para o deleite gastronômico dos seres humanos. Inobstante, há milhões de pessoas subnutridas em inúmeros países, o que, em princípio, aponta para uma falha no sistema da compartimentalização, seja das monoculturas, seja da criação industrial de animais.

Chiavenato sugere que o modo de produção de alimentos adotado por vários países ocidentais - a alimentação capitalista - estaria diretamente relacionado à fome na atualidade. Observa ele que, na década de 1980, um terço da população comia $65 \%$ dos alimentos produzidos, considerando-se que, à época, ainda subsistia a divisão entre países capitalistas e países socialistas. Do mesmo modo, as supersafras de grãos eventualmente obtidas no Brasil, às quais os governos e os meios de comunicação social tecem loas, têm como objeto produtos para exportação, tais como a soja, que, na maioria das vezes, já foram antecipadamente negociados (9). Nesse contexto, resta evidente que tais supersafras são inservíveis para saciar a necessidade alimentar da população brasileira, de vez que direcionadas ao mercado exterior, usualmente, para a fabricação de ração animal; a mesma situação de insegurança alimentar encontra-se presente em vários outros países.

Veja-se que Chiavenato escreveu sobre a falácia das supersafras em 1987, mas essa realidade permanece até os dias de hoje. No ano de 2013, mais uma supersafra de grãos foi anunciada com estardalhaço por autoridades e participantes do agronegócio, sendo que estes, após enfrentarem dificuldades para seu escoamento, referiram-se à "tragédia da falta de infraestrutura adequada" para encaminhar o produto, tempestivamente, aos mercadores consumidores. Sobre o tema, a Revista Exame veiculou matéria entitulada "A supersafra vira tragédia por falta de infraestrutura", esclarecendo que "o fiasco no escoamento da soja, para nossa vergonha, vai correr o mundo como piada: o Brasil é um país que produz e vende, mas não consegue entregar" (10). Novamente, verifica-se que o escopo da monocultura adotada é vender, mas não alimentar, porquanto nenhuma preocupação é revelada para com o mercado consumidor de alimentos interno.

Demais disso, é imperioso lembrar que o modelo da monocultura esbarra em fortes

${ }^{2} \grave{A}$ guisa de exemplo, veja-se a notícia divulgada pelo jornal Zero Hora sob a manchete "Perdas na avicultura no Rio Grande do Sul somam mais de $\mathrm{R} \$ 5,4$ milhões" (8). 
limitações ecológicas, dado que sobremaneira dependente de insumos externos para manter seu equilíbrio dinâmico. Tal modelo não subsiste sem o aporte gigantesco de adubos e fertilizantes, herbicidas, pesticidas e fungicidas, pois ancorado num modo de produção do conhecimento que não reconhece outros saberes além daqueles cartesianos, dotados da pretensão da universalidade, adotados no mundo occidental (4). Como percucientemente observado por Flores, De Gregori e Araújo, a "industrialização do modelo agrícola impeliu a ideia de que o melhoramento e a produção das variedades deveriam ser manejados apenas por profissionais especializados, 'legitimados' pela ciência [...]" (11).

Além disso, a manipulação desmesurada da natureza, com a escusa de aumentar a produtividade do solo ou de proteger determinada planta, não é garantia de segurança alimentar. Ao contrário, a adoção dessa conduta tende a trazer como resultados o desequilíbrio do ecossistema e, mesmo, a criação de pragas muito mais resistentes. Um exemplo de consequência desastrosa da utilização de um produto químico foi o caso do DDT, que foi indicado, por técnicos, aos fazendeiros da Lousiana, nos Estados Unidos, para exterminar as lagartas-caruncho que assolavam os algodoais. O veneno foi aplicado e as primeiras safras que se seguiram foram salvas, mas, gradualmente, foram necessárias cada vez mais aplicações, diante da evolução das lagartas, que se adaptaram até tornarem-se imunes ao produto. Quando isso ocorreu, os agricultores passaram a utilizar pesticidas ainda mais fortes, o que conduziu à criação de lagartas resistentes a todos os produtos dessa espécie, forçando os produtores ao abandono dos algodoais em alguns estados norteamericanos (9).

Ademais, a intensa utilização desses produtos tende a alterar também a fauna das áreas que deram origem às plantações. De efeito, a derrubada paulatina da vegetação nativa e a presença de produtos químicos, tanto no solo e nas plantações - para os quais, em tese, teriam sido desenvolvidos - quanto no próprio ar, acabam por expulsar inúmeros animais dessas regiões. Sobre o tópico, a pertinente observação de Chiavenato:

As minhocas desapareceram das roças de cana ou de soja. Quem ainda não viu as rolinhas, andorinhas, pardais ou outras aves, "invadirem" aos bandas as antenas de televisão nas cidades? Elas fogem das roças, onde já não sobram árvores e, principalmente, onde não se pode mais respirar nem comer: o veneno poluiu o ar e matou os insetos que as alimentavam (9).

Importa registrar, ainda, que a intervenção humana na natureza tem levado à diminuição do número de polinizadores naturais para a agricultura - tais como abelhas e 
moscas - o que é extremamente preocupante, dado que a polinização é um processo-chave para garantir a produtividade agrícola. À guisa de exemplo, Bensusan observa que estão faltando polinizadores nas plantações de cacau em razão da adoção de técnicas que prescrevem a remoção dos restos vegetais onde eles se desenvolviam (1).

Da mesma forma, Bensusan lembra que o maior consumo de água provém da agricultura, representando $86 \%$ do consumo total anual na Ásia, o que também representa uma ingerência indevida nos ecossistemas. A cultura do arroz é a maior consumidora, de vez que se necessita de cerca de 5000 litros de água para se produzir um quilo de arroz. No entanto, concomitamente, há 900 milhões de casos por ano de diarreia e 7 milhões de mortes anuais por causa de doenças transmitidas pela água no mundo (1).

No que concerne à criação industrial de animais, veja-se que, na década de 1970, já se verificava que os alimentos desperdiçados pela produção animal nas nações desenvolvidas seriam suficientes para acabar com a fome no mundo, caso fossem distribuídos apropriadamente. Ocorre que a criação nesses moldes consome uma série de recursos, que poderiam ser destinados à produção de outros alimentos que atingiriam um número muito maior de seres vivos.

A energia demandada pela indústria pecuária, por exemplo, é muito maior do que a energia contida no alimento por ela produzido. O mesmo problema se põe no que tange à utilização de água, que é necessária em imensas quantidades para a produção de alimentos de origem animal, além de ser também desperdiçada em grande volume, o que está conduzindo ao esgotamento dos lençóis subterrâneos dos quais dependem as regiões mais áridas dos Estados Unidos e Austrália, dentre outros países. Demais disso, a devastação das florestas é consequência direta da demanda por alimentos de origem animal. No Brasil, Colômbia, Costa Rica, Indonésia, Malásia e Tailândia, florestas tropicais são derrubadas para prover áreas de pastagem para o gado. A destruição das florestas conduz à extinção das espécies animais e vegetais que habitam esses ecossistemas, provoca erosão e diminuição no regime pluvial, além de intensificar o efeito estufa. Contudo, a maior parte da carne produzida é direcionada à venda nas grandes cidades ou à exportação, não beneficiando, destarte, a população economicamente menos favorecida desses países (2).

Constata-se, assim, que existe uma dissociação entre o modo de produção de alimentos adotado - um modelo industrial, dependente de insumos externos e voltado ao mercado exterior - e a finalidade que deveria orientá-lo, a saber, a alimentação. 


\section{A (in)adequação do modelo à sua finalidade: a possível resposta jurídica}

A destruição das florestas, o uso excessivo de agrotóxicos para sustentar a dependência química das culturas e o aumento dos latifúndios produtores das monoculturas destinadas à exportação são apontados por Flores, De Gregori e Araújo como as bases sobre as quais se assenta a modernização agrícola (11).

Veja-se que a agricultura implica a seleção, eleição e invenção de determinadas espécies, o que pode torná-las mais vulneráveis, e que a transformação de um ecossistema num agrossistema tem como consequência inafastável a perda de diversidade biológica (4). Ademais, lembra Shiva que "as estratégias da engenharia genética voltadas para a resistência e que estão destruindo espécies de plantas úteis também podem acabar criando superervas-daninhas" (6). Concomitantemente, ocorre a disseminação cada vez maior de organismos geneticamente modificados ao fundamento de que isso é necessário para aumentar a produção mundial de alimentos, para permitir, assim, a alimentação adequada de toda a população mundial.

No entanto, impende registrar, os riscos de consumir alimentos produzidos a base de agrotóxicos ou geneticamente modificados não estão sendo adequadamente considerados na equação da fome, tampouco o fato de que a maior parte dos produtos das monoculturas é direcionada a um mercado exterior ao local onde são produzidos, não se prestando, destarte, a alimentar os próprios trabalhadores que os criaram. Como pertinentemente consignado por Flores, De Gregori e Araújo, “o dilema entre o aumento da produção agrícola, mesmo que com ameaças à saúde, e o aumento da fome, causado pela falta de alimentos disponíveis é, no entanto, sabidamente falso" (11).

Shiva aponta a insustentabilidade das monoculturas, asseverando que estas têm como característica, não apenas substituir as alternativas, mas também destruir a sua base. No caso da silvicultura, lembra ela que a produtividade da floresta baseia-se ecologicamente em sua diversidade, a qual é destruída pelo sistema comercial, conduzindo à sua degradação e ao solapamento de sua sustentabilidade. No que concerne à agricultura, as variedades de sementes introduzidas pela Revolução Verde substituíram as safras cultivadas de forma tradicional - as quais dispunham de um sistema inato de proteção extirpando a diversidade e gerando um verdadeiro mecanismo de introduzir e aumentar as pragas que se autorreproduz; como consigna a filósofa indiana, "a grande roda de criação de novas variedades gira incessantemente à medida que variedades ecologicamente 
vulneráveis criam novas pestes, que criam a necessidade de criar outras novas variedades" (6). Assevera, assim, que a agricultura sustentável tem por base a reciclagem dos nutrientes do solo, o que se dá a partir da devolução ao solo dos nutrientes que dele advêm, lembrando que "as tecnologias não têm condições de substituir a natureza e o trabalho fora dos processos ecológicos da natureza sem destruir a própria base da produção" (6).

No mesmo sentido, Porto-Gonçalves consigna que as monoculturas têm provocado a dissociação entre agricultura, pecuária e extrativismo, opondo-se, desse modo, à garantia de segurança alimentar buscada pela humanidade:

A monocultura de alimentos (e outras) é, em si mesma, a negação de todo um legado histórico da humanidade em busca da garantia da segurança alimentar na medida em que, por definição, a monocultura não visa a alimentar quem produz e, sim, a mercantilização do produto. [...] Não raro as regiões especializadas em agricultura de exportação, sobretudo na Ásia, na África e na América Latina e Caribe, vivem frequentemente diante da insegurança alimentar, não só porque os melhores solos são destinados a produzir para fora, como é concentrada a propriedade da terra (4).

No Brasil, a definição de segurança alimentar é dada pela Lei $n^{\circ} 11.346 / 06$ - que cria o Sistema Nacional de Segurança Alimentar e Nutricional - SISAN com o fito de assegurar o direito humano à alimentação adequada - em seu artigo $3^{\circ}$ :

Art. $3^{\circ}$. A segurança alimentar e nutricional consiste na realização do direito de todos ao acesso regular e permanente a alimentos de qualidade, em quantidade suficiente, sem comprometer o acesso a outras necessidades essenciais, tendo como base práticas alimentares promotoras de saúde que respeitem a diversidade cultural e que sejam ambiental, cultural, econômica e socialmente sustentáveis (12).

Como alhures referido, o escopo das monoculturas e da criação industrial de animais é vender alimentos, mas não alimentar, e essa pauta é de ser questionada na realidade fática da sociedade de risco, bem como em face do Direito Ambiental, em especial, do princípio da precaução.

Sarlet e Fensterseifer - lembrando Ulrich Beck - observam que os conhecimentos tecnológicos e científicos - cujo escopo deveria ser o desenvolvimento, o bem-estar social e a dignidade e qualidade da vida humana - tornaram-se a principal ameaça à sobrevivência das espécies e ao ecossistema planetário, em razão de sua instrumentalização inconsequente realizada pelo homem, caracterizando, destarte, um modelo de sociedade de risco. A esse modelo, agregam os autores as ideias de Hans Jonas, que se refere à 
"civilização tecnológica", propondo uma abordagem ética da ciência expressa no princípio da responsabilidade, tendo em conta os riscos trazidos pelas novas tecnologias (13).

O reconhecimento de que certos riscos devem ser objeto de tratamento político e jurídico é uma marca da constituição de uma sociedade de risco, na qual insere-se, dentre as funções do Poder Público, verificar a existência de possíveis perigos e buscar os meios de evitá-los ou neutralizá-los, com o auxílio das ciências e das técnicas. Assim, torna-se necessária a produção de normas e a criação de institutos e instituições específicas ou, ao menos, adaptadas a esse modelo de sociedade, com a consequente reformulação do Pacto Social do século XVIII, fruto das liberdades individuais pugnadas pela burguesia politicamente ascendente e que conduziu ao Estado Liberal (14).

Sobre o tema, Hermitte aponta a necessidade de reconhecer que as ciências e as técnicas integram o governo dos homens e que os riscos por elas produzidos não podem ser desconsiderados, impondo-se "inscrever as ciências, as técnicas e seus riscos na hierarquia das normas para dar-Ihes um fundamento coerente em vez de regulamentar de forma casual". Aduz, ainda, a necessidade de modificar a relação entre governantes e governados, no sentido de, em havendo o reconhecimento da existência de um risco, buscar-se uma decisão democrática sobre submeter-se ou não a ele, bem como sobre a equidade da distribuição desse risco (14).

São da natureza do risco ambiental que as decisões sejam tomadas num universo controverso e incerto, o que impõe que o sistema jurídico esteja munido de princípios de ação, operadores, tais como os da prevenção, da precaução, da participação e do poluidor pagador, por exemplo, que asseguram previsão, antecipação, legitimidade e responsabilidade respectivamente (15).

Nesse contexto, é evidente que a atuação do Poder Público não deve ser resumir apenas a estimular a economia de um dado país - por exemplo, fornecendo subsídios, facilitando linhas de crédito ou quaisquer outras benesses aos participantes do agronegócio. Ao contrário, inobstante seja imperioso reconhecer a relevância desse setor na economia, o estímulo governamental deve visar ao bem comum, nisso incluído o fornecimento de alimentos saudáveis e adequados para sua população e o devido respeito à natureza e seus recursos.

Ademais, a utilização predatória da natureza acarreta consequências que desequilibram a equidade entre as gerações, quais sejam o esgotamento de recursos, a 
degradação da qualidade ambiental e o acesso e uso discriminatório de recursos (16). Temse, assim, que o modelo de produção de alimentos atualmente adotado em vários países das monoculturas e da criação industrial de animais para consumo - não demonstra, de forma cabal, ser sustentável em longo prazo, pondo em risco a segurança alimentar das gerações futuras.

No ponto, importa lembrar a Teoria da Equidade Intergeracional, proposta por Weiss, segundo a qual, cada geração é, por sua vez, guardiã e usuária do patrimônio comum natural e cultural, sendo sujeito de obrigações e direitos planetários. A referida teoria propugna pela observância dos princípios da equidade intergeracional, os quais conduzem às obrigações planetárias supracitadas, consubstanciados em princípio da conservação das opções, princípio da conservação da qualidade e princípio da conservação do acesso. Dentre as obrigações planetárias, lembra a autora a existência dos deveres de uso, à geração atual, de conservar os recursos, assegurar seu uso equitativo e evitar impactos desfavoráveis (16). Por tal razão, impõe-se à geração atual considerar, ao adotar determinado modelo de produção, se este permitirá a segurança alimentar necessária também às gerações que lhe sucederão, observando os indigitados princípios.

Demais disso, além dos princípios arrolados por Weiss, importa perquirir se o modelo de produção de alimentos da monocultura e da criação industrial de animais está em conformidade com o princípio da precaução.

Os princípios do Direito Ambiental constituem normas destinadas a otimizar a tutela jurídica do meio ambiente, projetando-se para todas as demais normas ambientais e norteando sua aplicação, observados os objetivos e diretrizes do sistema desse ramo do Direito, além de atuarem como instrumentos de integração. No caso brasileiro, vários desses princípios estão positivados na Carta Constitucional de 1988, tais como os da participação popular, do desenvolvimento sustentável, da precaução e da prevenção (17). Na questão atinente à relação entre os modelos de produção de alimentos e a alimentação, impõe-se observar os ditames do princípio da precaução.

O princípio da precaução ingressou no Direito Ambiental na década de 1970, com o escopo de reduzir ou eliminar os riscos de danos à saúde e ao meio ambiente, embora remonte ao início do Século XX, quando surgiram as primeiras menções ao Vorsorgeprinzip, no direito alemão. O princípio está consagrado no Enunciado 15 da Declaração do Rio de Janeiro nos seguintes termos: 
Com o fim de proteger o meio ambiente, o princípio da precaução deverá ser amplamente observado pelos Estados, de acordo com suas capacidades. Quando houver ameaça de danos graves ou irreversíveis, a ausência de certeza científica absoluta não será utilizada como razão para o adiamento de medidas economicamente viáveis para prevenir a degradação ambiental (18).

A utilização do princípio da precaução dirige-se ao perigo abstrato, diferentemente do princípio da prevenção, que se dá em relação ao perigo concreto (19). O princípio da precaução é aplicável nas hipóteses de incerteza científica acerca dos riscos ambientais concretos decorrentes de determinada atividade, impondo uma ação que se antecipe ao risco ou perigo de dano ao meio ambiente, uma conduta anterior à concretização do possível dano. Por tal razão, deve ser aplicado com o escopo de reduzir a extensão, a frequência ou a incerteza do dano, embora, por óbvio, sem imobilizar as atividades humanas. Sua finalidade consiste em garantir a durabilidade da sadia qualidade de vida e a continuidade da natureza existente no planeta (20).

Trata-se de princípio em constante evolução, que determina a adoção de medidas de precaução sempre que constatadas novas ameaças, razão pela qual o grau de desenvolvimento técnico e científico de avaliação do impacto ambiental é determinante para a correta perquirição dos riscos e possíveis danos decorrentes de cada atividade (17). Sobre o tópico, sustenta Machado que o risco ou perigo devem ser analisados conforme o setor que puder ser atingido pela atividade ou obra, considerando o custo das medidas de prevenção aplicáveis em relação ao país, à região ou ao local (20).

Esse princípio sofre constantes críticas dos defensores da liberdade ilimitada, que advogam a necessidade de comprovação da lesividade ao meio ambiente ou à saúde pública para que novas técnicas ou atividades sejam barradas. Fundamentam-se eles, no caso do ordenamento jurídico brasileiro, no próprio texto constitucional, nos valores da livre iniciativa (artigo $1^{\circ}$, IV, segunda parte) e nos direitos da livre expressão da atividade científica e da propriedade (artigo $5^{\circ}$, incisos IX e XXII) e nos princípios da Ordem Econômica (artigo 170), inclusive na garantia de livre exercício da atividade ecônomica conforme o parágrafo único do artigo 170 (21).

Todavia, também o direito ao meio ambiente sadio e ecologicamente equilibrado é direito fundamental positivado na Constituição e a Ordem Econômica Constitucional há de observar não apenas os princípios favoráveis à livre iniciativa, mas também a defesa do 
meio ambiente, conforme disposto no inciso VI, do artigo 170, da Lei Maior (21). No ponto, Figueiredo pertinentemente esclarece a falta de lastro das críticas ao princípio da precaução, asseverando que não pode "o ordenamento jurídico autorizar aos cientistas que aceitem o risco difuso como se este fosse individualizável e perfeitamente delimitado no espaço e no tempo, alcançando somente os beneficiários da empresa pretendida" (17).

Da mesma forma, assevera Machado que a Constituição Federal, no artigo 225, $\S 1^{\circ}$, inciso $\mathrm{V}$, determina que "o Poder Público não se omita no exame das técnicas e métodos utilizados nas atividades humanas que ensejem risco para a saúde humana e o meio ambiente" (20). O multicitado princípio atua quando há certeza da incerteza científica, impondo uma atuação cautelosa do Poder Público e da sociedade. No mesmo sentido, Hermitte lembra que o princípio da precaução é "um princípio de pesquisa científica contínua e de adaptação não menos permanente da decisão política aos conhecimentos científicos" (14). Assim, a partir do reconhecimento e da aceitação da existência do risco, a tomada de decisão passa a se dar sobre uma situação de incerteza, impondo uma estratégia antecipativa, própria do princípio da precaução, pelo qual a dúvida beneficia o meio ambiente (15).

O princípio da precaução constitui, simultaneamente, um dever, que reforça a ideia de uma nova ética para a conduta humana, a partir da assunção de responsabilidade para além da dimensão temporal presente, num reconhecimento do elo existencial e interdependência entre as gerações presentes e futuras. Tal princípio conecta-se ao princípio da responsabilidade, alhures referido, num contexto em que a solidariedade e os deveres fundamentais do Poder Público e dos particulares para com o meio ambiente detêm papel central. Nesse contexto, Sarlet e Fensterseifer propõe a migração da ética da responsabilidade, na esteira da dimensão moral, para a esfera jurídica dos deveres constitucionais de proteção ao ambiente, inclusive com a limitação de direitos fundamentais do ser humanos, como a autonomia da vontade, se necessário para assegurar a existência digna e saudável das gerações presentes e futuras (13).

Por evidente, a utilização do indigitado princípio não visa ao engessamento das ações governamentais ou tampouco dos produtores rurais na busca de melhores técnicas que assegurem maior produtividade e menos danos à natureza. A finalidade é, ao contrário, permitir que a utilização da natureza na produção de alimentos tenha por escopo efetivamente alimentar os seres vivos, sem conduzir ao esgotamento dos recursos naturais 
ou à geração de situações que venham a por em risco a segurança alimentar das populações.

\section{Conclusão}

No decorrer do texto, buscou-se investigar as relações que se põem entre o modo de produção de alimentos, de origem vegetal ou animal, que segue os padrões industriais e a permanência, na atualidade de um grande número de pessoas subnutridas ou indevidamente alimentadas, tendo em conta uma perspectiva que considera a realidade fática da sociedade de risco e as normas do Direito Ambiental, notadamente, o princípio da precaução.

Verificou-se, inicialmente, que, a partir do advento da Idade Moderna e considerando as vastas extensões de terra do continente americano que foram repartidas entre poucas nações europeias, foi adotado um modelo de produzir alimentos que se diferenciava daquele utilizado até então e que se baseava num contato mais íntimo e muito mais respeitoso com a natureza. De efeito, os conquistadores passaram a plantar poucos produtos em enormes áreas, utilizando-se, assim, de monoculturas, cujas plantações substituíam o lugar antes ocupados pelos produtos cultivados pelos povos locais e avançavam sobre as fronteiras naturais das vegetações nativas. A mesma lógica produtiva foi transposta para outras regiões do planeta, tal como a Ásia, que, embora berço de civilizações milenares, como a indiana e a chinesa, também sofreu a sanha imperialista das nações europeias que, constrangidas em suas diminutas dimensões e pressionadas pelos conflitos que há séculos caracterizavam aquele continente, buscavam expandir-se.

Constatou-se que, embora o modelo industrial seja considerado "científico", o que, em tese, implicaria uma melhor utilização dos recursos naturais com uma consequente maior produtividade, os resultados de sua adoção não garantem segurança alimentar. Ao contrário, no que concerne à agricultura, tal modelo é extremamente dependente de insumos externos; vulnerável a variações climáticas e pragas, podendo conduzir a situações dramáticas, tal como a da "grande fome das batatas" na Irlanda, narrada nas considerações iniciais deste artigo. Ademais, é agressivo à natureza, conduzindo à degradação da vegetação e alterações negativas na fauna local. Sorte semelhante acode à criação de animais em escala industrial, que consome inúmeros recursos, que seriam muito melhor utilizados se destinados à produção de outros alimentos que atingiriam um número expressivamente 
maior de seres vivos.

Além das questões ecológicas, por evidente, consignou-se a existência de uma falha na questão da distribuição dos alimentos produzidos na lógica industrial. As monoculturas produzem commodities que, de regra, são destinados ao mercado externo, contribuindo para a melhoria da imagem da economia do país, mas não se prestando para alimentar os trabalhadores que os produziram, os quais permanecem, assim, alienados do fruto do seu trabalho. Da mesma forma, o destino da carne e demais derivados dos animais criados no regime industrial são as grandes cidades e o exterior.

Vistos os atributos do modo de produção de alimentos das monoculturas e da criação industrial de animais, passou-se ao cotejo desse modelo à noção de sociedade de risco e à verificação de sua (in)adequação ao princípio da precaução.

Assumindo-se que os conhecimentos tecnológicos e científicos, produzidos pelos seres humanos, tornaram-se uma ameaça à sobrevivência das espécies e ao ecossistema ao invés de se pautarem pela busca da dignidade e do bem-estar, que deveriam ser suas finalidades, impõe-se que os riscos daí decorrentes sejam objeto de tratamento político e jurídico. Nesse contexto, cabe ao Poder Público investigar a existência de possíveis perigos, procurando os meios de evitá-los ou neutralizá-los, o que determina que a técnica e a ciência passem a integrar o discurso político e jurídico, ao menos, no que concerne às questões ecológicas. Da mesma forma, torna-se necessária a criação de instituições e institutos hábeis a lidar com a questão dos riscos, bem como a produção de normas jurídicas voltadas ao modelo da sociedade de risco. Concomitantemente, é imperiosa a adoção de uma abordagem ética da ciência, a partir do princípio da responsabilidade, de modo a conferir legitimidade às inferências e conclusões científicas que, oportunamente, fundamentarão as decisões políticas e jurídicas.

Na mesma senda, importa adotar uma perspectiva principiológica quanto à questão alimentar. De efeito, o modo de produção de alimentos há de observar os princípios da equidade intergeracional, a saber, conservação das opções, conservação da qualidade e conservação do acesso, os quais conduzem à existência de obrigações planetárias à geração presente, dentre as quais se salientam os deveres de uso de conservar os recursos, assegurar seu uso equitativo e evitar impactos desfavoráveis.

Além disso, impende perquirir se o modelo de produção de alimentos da monocultura e da criação industrial de animais está em conformidade com o princípio da precaução, o 
qual, como os demais princípios do Direito Ambiental, trata-se de norma destinada a otimizar a tutela jurídica do meio ambiente, porém cujo fim específico é garantir a durabilidade da sadia qualidade de vida e a continuidade da natureza existente no planeta. Como alhures referido, o princípio da precaução dirige-se ao perigo abstrato, sendo aplicável nas hipóteses de incerteza científica acerca dos riscos ambientais concretos decorrentes de determinada atividade, a fim de reduzir a extensão, a frequência ou a incerteza do dano.

Evidentementemente, o princípio da precaução não visa à paralisação das atividades humanas econômicas ou científicas, mas sim à adoção de medidas de cautela sempre que constatadas novas ameaças, as quais podem ser verificadas a partir da perquirição dos riscos e possíveis danos decorrentes de cada atividade. Assim, tem-se que as críticas que essa norma recebe dos advogados da liberdade ilimitada - tão típica do Estado Liberal e individualista, que se limitava a proteger as liberdades burguesas, a partir da premissa contratual - não encontram lastro. Ora, o meio ambiente - e, nesse conceito, devem ser incluídos os modelos de produção de alimentos - é direito fundamental de todos, sobrepujando, evidentemente, os interesses meramente econômicos do agronegócio, que beneficia apenas os seus titulares.

Nesse contexto, a adoção do indigitado princípio, no que concerne à produção de alimentos, caracteriza uma forma de utilização da natureza que não conduz ao esgotamento dos recursos, à existência de situações de risco à segurança alimentar e à desigual distribuição dos produtos, mas sim a modelos de agricultura e de criação de animais que coexistem com os ecossistemas sem violá-los e cuja finalidade é, efetivamente, alimentar os seres vivos.

\section{Referências}

1. Bensusan N. O que a natureza faz por nós: serviços ambientais. In: Bensusan, N. (org.) Seria melhor mandar ladrilhar? Biodiversidade: como, para que e por quê. Brasília: Editora UnB, 2008.

2. Singer P. Libertação animal. Tradução: M. Winckler; MB. Cipolla. São Paulo: WMF Martins Fontes, 2010.

3. Organização das Nações Unidas para Alimentação e Agricultura - FAO. Mapa da fome. Disponível em: http://www.fao.org/state-of-food-security-nutrition/en/ [ Acesso em 27.jul.2014]. 
4. Porto-Gonçalves CW. A globalização da natureza e a natureza da globalização. Rio de Janeiro: Civilização Brasileira, 2006.

5. Galeano E. Úselo y tírelo: el mundo del fin del milenio visto desde una ecología latinoamericana. Buenos Aires: Planeta Argentina, 1994.

6. SHIVA V. Monoculturas da mente: perspectivas da biodiversidade e da biotecnologia. Dinah de Abreu Azevedo (trad). São Paulo: Gaia, 2003.

7. Descartes R. Discurso do Método. Maria Ermantina de Almeida Prado Galvão (trad). São Paulo: WMF Martins Fontes, 2011.

8. Colussi J. Perdas na avicultura no Rio Grande do Sul somam mais de R $\$ 5,4$ milhões. Zero Hora, Porto Alegre, 14 fev. 2014. Disponível em: https://gauchazh.clicrbs.com.br/economia/campo-e-lavoura/noticia/2014/02/perdas-naavicultura-no-rio-grande-do-sul-somam-mais-de-r-5-4-milhoes-4418964.html [Acesso em 25. jul. 2014].

9. Chiavenato JJ. O massacre da natureza. São Paulo: Moderna, 1989.

10. Vassalo C. A supersafra vira tragédia por falta de infraestrutura. Revista Exame. 3 abr 2013. Disponível em: https://exame.abril.com.br/revista-exame/a-supersafra-viratragedia/ [Acesso em 24.jul.2014].

11. Flores MP, De Gregori MS, Araujo LEB. A segurança alimentar e os modelos de produção agrária químico-dependentes. Revista Eletrônica do Curso de Direito da UFSM. 2013; 8:318-328.

12. Brasil. Lei $\mathrm{n}^{0}$ 11.346, de 15 de setembro de 2006. Planalto. Disponível em: http://www.planalto.gov.br/ccivil 03/ Ato2004-2006/2006/Lei/L11346.htm. [Acesso em 13.jul.2017.

13. Sarlet IW, Fensterseifer T. Direito constitucional ambiental: Constituição, direitos fundamentais e proteção do ambiente. São Paulo: Revista dos Tribunais, 2012.

14. Hermitte MA. A fundação jurídica de uma sociedade das ciências e das técnicas através das crises e dos riscos. In: Varella MD (org.). Direito, Sociedade e Riscos: sociedade contemporânea vista a partir da ideia de risco. Rede Latino-Americana e Europeia sobre Governo dos Riscos, Brasília, 2006.

15. Labrot V. Droit et complexité. Regard sur le droit de l'environnement. In: Doat M, Le Goff J, Pedrot P (dir.). Droit et complexité: pour une nouvelle intelligence du droit vivant. Rennes: PUR, 2007.

16. Weiss EB. Un mundo justo para las futuras generaciones: derecho internacional, patrimonio común y equidad intergeneracional. Máximo E. Gowland (trad). Madrid: MundiPrensa, 1999. 
17. Figueiredo GJP. Curso de Direito Ambiental. São Paulo: Revista dos Tribunais, 2012.

18. Organização das Nações Unidas. Declaração do Rio de Janeiro sobre Meio Ambiente e Desenvolvimento, junho de 1992. Disponível em: http://www.onu.org.br/rio20/img/2012/01/rio92.pdf. [Acesso em 28.mai.2014].

19. Leite JRM, Ayala PA. Direito Ambiental na Sociedade de Risco. Rio de Janeiro: Forense Universitária, 2002.

20. Machado PAL. Direito Ambiental Brasileiro. São Paulo: Malheiros, 2008.

21. Brasil. Constituição da República Federativa do Brasil de 1988. Disponível em: http://www.planalto.gov.br/ccivil 03/Constituicao/Constituicao.htm. [Acesso em 24.jun.2017].

Como citar este artigo:

Azevedo JL. O modelo industrial de produção de alimentos sob a perspectiva da sociedade de risco e do princípio da precaução. Revista Cadernos Ibero-Americanos de Direito Sanitário. 2018 jan./mar, 7(1):43-62. 